\title{
Do novo ao tradicional: a representação da psicologia no judiciário
}

\section{From the new to the traditional: the representation of psychology in the judiciary}

\author{
Verônica Cecilia Alves da Silva Mafra* \\ Tribunal de Justiça de Pernambuco - TJ/PE, Boa Vista, Recife, Pernambuco, Brasil \\ Maria de Fátima de Souza Santos** \\ Universidade Federal de Pernambuco - UFPE, Cidade Universitária, Recife, \\ Pernambuco, Brasil
}

\begin{abstract}
RESUMO
Este estudo teve como objetivo investigar as representações sociais de psicólogos que trabalham no Poder Judiciário de Pernambuco, acerca da psicologia jurídica. Dele participaram 56 psicólogos. Utilizou-se um questionário, com uma fase de associação livre ao termo indutor psicologia jurídica. As informações daí advindas foram tratadas com o programa de computador de análise de evocações EVOC. Os resultados demonstraram que a psicologia jurídica é representada por estes profissionais como campo de aplicação dos conhecimentos psicológicos e de atuação profissional que está se constituindo e diz respeito às questões legais, sendo um espaço marcadamente de interface. Os dados demonstram também que neste espaço convivem o conhecimento científico e o conhecimento comum. Conclui-se que reconhecer as tensões e conflitos deste campo, assim como as representações paralelas à reformulação teórica e técnica, pode subsidiar o processo crítico de transformações na atuação profissional.

Palavras-chave: Psicologia Jurídica, Atuação profissional, Representação social.
\end{abstract}

\begin{abstract}
This study had the objective of investigating the social representations of the psychologists who work in the Judiciary Power of Pernambuco about judicial psychology. Fifty-six psychologists took part in it by answering a questionnaire with a phase of free association to the inductive term "judicial psychology". The resulting information was treated with the use of the software EVOC for evocation analysis. The results demonstrated that judicial psychology is represented by these professionals as a field of psychological knowledge application and professional performance which is being formed and concerns legal matters. It is markedly an interface space. Data also show that scientific knowledge and common knowledge coexist in this area. In conclusion, recognizing the tensions and conflicts of this field, as well as the representations parallel to the theoretical and technical reformulation, can subsidize the critical process of transformation in professional performance.
\end{abstract}


Key words: Judicial Psychology, Professional performance, Social representation.

\section{Introdução}

A Psicologia adjetivada de jurídica tem sido concebida diferentemente pelos estudiosos que dela se ocupam. Na literatura que a ela se refere, ora se encontra a menção à aplicação da disciplina psicológica ao campo jurídico, como conhecimento autônomo e especializado, requerendo o revisitar ou a ampliação de seu arcabouço teórico e técnico. Ora se encontra a concepção de que ela se constitui em uma área nova de prática dos psicólogos, trazendo desafios e exigências na elaboração de estratégias metodológicas adequadas.

A diferença de visões e a tentativa de oferecer contornos a este que se apresenta como "campo novo" da Psicologia foram bem ilustradas, entre outros, por Miranda Júnior (1998), Brito (1999) e França (2004) e exigem o delineamento dos termos jurídico e judiciário, assim como do que se quer designar como psicologia judiciária. Enquanto a Psicologia Jurídica parece dizer respeito de forma bastante abrangente às questões da subjetividade e das relações humanas que mantêm alguma interface com o Direito e as leis; a Judiciária ou Forense estaria ligada diretamente à atividade judicante (LOBÃO, 1997, apud ASSIS, 1999). Ainda que com raio de ação mais restrito, esta última vem requerer, assim como a Psicologia Jurídica, um repensar constante de seus pressupostos e de sua prática.

Ainda na tentativa de delinear esses campos, podem ser tomadas as definições apresentadas pelo Dicionário Houaiss da língua portuguesa para os termos jurídico e judiciário, e aí constatar que jurídico se refere ao que é relativo ao direito, ao que está em conformidade com os princípios do direito, ao que se faz por via da justiça, ao que é lícito, legal e, por fim, ao que é relativo à justiça. Enquanto judiciário irá se referir ao Poder Judiciário, ao que é relativo a juízes e a processo judicial, como também à justiça. Depreende-se aqui também uma maior amplitude para o jurídico e uma localização mais delimitada para o termo judiciário.

Contudo, embora essas definições possam levar à compreensão de que a denominação de psicologia judiciária esteja ligada ao lugar em que o profissional psicólogo desenvolve sua prática, concorda-se com Bernardi (1999) quando ela ressalta que "A Psicologia Judiciária, mais que um nome a definir lugar, tem sido um espaço amplo e contraditório, no qual os profissionais da área inscrevem suas ações e com elas todo um dispositivo de saber que, ao ser construído por eles, os constrói a todos" (2005, p.24). Assim, neste estudo optou-se por adotar a denominação mais ampla, a de Psicologia Jurídica. 
Além disso, foi preciso considerar, como propõem Gondim, Bastos e Peixoto (2010), que o desafio da construção de novas estratégias metodológicas pelo psicólogo se impõe além da inserção no campo jurídico, pois diz respeito ao fato de que ao longo de sua constituição como ciência e profissão haver a psicologia se dedicado a diferentes temáticas, a diferentes áreas. Além disso, cumpre lembrar que neste percurso seu perfil profissional foi ampliado, sobretudo com a sua inserção em organizações públicas e a necessidade de adaptar-se às galopantes transformações operadas pela globalização e pela informatização no mundo do trabalho, conforme alertado por Heloani, Macêdo e Cassiolato (2010).

Nesta perspectiva, se buscou abrir espaço para que o psicólogo assuma a posição, quiçá filosófica, de interrogar a Psicologia, sua constituição, sua "razão de ser". Interrogar a sua intenção, como o fez George Canguilhem (1999) no texto O que é a psicologia?. A importância desse estudo reside, pois, na oportunidade de colaborar com a ampliação do conhecimento da ciência psicológica, oferecendo subsídios para pensar sua prática institucional.

Ao discutir na década de 1990 o panorama da Psicologia no Brasil, Yamamoto e Campos (1997) resgatam estudos anteriores que a caracterizavam como "elitista" e mesmo reconhecendo a possibilidade da constituição de novos espaços e da emergência de práticas inovadoras a serem edificadas pelos psicólogos na inserção em contextos antes não "visitados", condicionam esta possibilidade ao fato de se estar consciente do processo pelo qual tal inserção se faz. More, Leiva e Tagliari (2001) ao analisarem a inserção da Psicologia em espaços comunitários de saúde, e em instituições públicas de forma mais geral, ressaltaram que a mesma tem levado à revisão do conhecimento que a sustenta, posto que ao passar do privado ao público o conhecimento psicológico, para estas autoras, perdeu sua eficiência.

Torna-se extremamente pertinente, então, o convite de Jacó-Vilela (1999) para refletir sobre a inserção e prática da disciplina psicológica no "mundo jurídico", já que, conforme Yamamoto e Campos (1997) consideraram, o "campo forense" pode trazer a oportunidade do profissional se dedicar a novas demandas.

Não obstante muitas das circunstâncias descritas por Yamamoto e Campos (1997) como capazes de propiciar o "novo" (espaços não usuais, novo tipo de clientela, convicções de ordem política e metodologia não usual, como os grupos multidisciplinares) se façam presentes na inserção do psicólogo no âmbito jurídico, isso não garante que a prática aí desenvolvida não será convencional, que os modelos teórico-metodológicos tomados como aporte para essa prática não serão convencionais.

$\mathrm{O}$ que se pode constatar em Pernambuco e em outros estados como o Rio de Janeiro (Brito, 2005) é que mesmo em uma pequena parcela 
daquilo que se designa como a prática do psicólogo no campo jurídico, há uma variedade de propostas de intervenção, como também uma diversidade de compreensão do que vem a ser o seu objeto de estudo. Neste aspecto Sonia Rovinski considera que a Psicologia Jurídica é "um campo aberto a novas propostas de ação e de investigação. No entanto, observa-se certa dificuldade na integração dos saberes que a constituem, cuja fragmentação tende, muitas vezes, a gerar controvérsias e práticas diferenciadas." (2009, p. 18)

Ainda que a diversificação de práticas e de objetos de investigação possa derivar das características dos serviços onde se insere o psicólogo, um amplo rol de atribuições para quem atua ou atuará na área jurídica já foi definido pelo Conselho Federal de Psicologia em 2007, na resolução $\mathrm{n}^{\circ} 13$ que trata do título de especialista. E em meio às controvérsias e às diferentes práticas que são desenvolvidas pelos profissionais, percebe-se no discurso e expectativas da instituição judiciária certa tendência em situar o lugar da psicologia no da técnica de controle, da classificação e do ajustamento, esperando-se que o profissional exerça o estrito e "convencional" papel de avaliador (J ACÓ-VILELA, 1999; MIRANDA JÚNIOR, 1998), de perito, e que anuncie, por exemplo, a capacidade ou incapacidade dos avaliados para a permanência na coletividade, ou suas "potencialidades" para o crime (FOUCAULT, 1987).

Diante da convocação à Psicologia para que assuma o posto de controle, de classificação e de ajustamento, é preciso, como alertado por Arantes (2004), que seus operadores problematizem as demandas que Ihes são dirigidas e lembrem que seu papel é estratégico no processo de objetivação/subjetivação das realidades.

Partindo-se da pouca definição ou do desconhecimento acerca das atribuições do psicólogo no campo jurídico, do parco material bibliográfico ao qual se soma a pequena exploração da área nos meios acadêmicos e da concomitante necessidade de os psicólogos apreenderem seu campo de intervenção, porque ali desenvolvem seus trabalhos, chega-se à suposição de que há um cenário propício tanto para formulações teóricas, quanto para a construção de representações por parte destes profissionais.

Construção que se fará apoiada em valores, conceitos, práticas e em conhecimentos anteriormente adquiridos. Então, tem-se que, buscando entender e identificar os limites e as possibilidades da intervenção no espaço do judiciário, o psicólogo atribui sentidos para sua prática profissional. E, ao atribuir sentidos e construir significados para "seu fazer e seu pensar" como psicólogo, está constituindo um saber que, necessariamente, reflete suas redes de relação e seu posicionamento na sociedade.

Assim como pode ser situado o campo da psicologia jurídica como um campo de interfaces entre domínios de saber, sobretudo entre ela e o 
direito, agora também toma relevo a interface, que neste caso se refere ao universo psíquico, melhor dizendo cognitivo, e o universo da coletividade, o social. Foi essa perspectiva psicossociológica, do entre, do que se situa na inter-relação, que adotou Moscovici em 1961 para edificar a Teoria da Representação Social. Para ele, é na relação entre os seres humanos e o mundo, "entre nossos mundos internos e externos", que se situam as representações, estas vêm mediar a compreensão que o homem tem da realidade. Diz ele: "no que se refere à realidade, essas representações são tudo o que nós temos, aquilo a que nossos sistemas perceptivos, como cognitivos, estão ajustados" (MOSCOVICl, 2003, p. 32).

Essas representações funcionariam como convenções, a recortar da realidade aquilo que será percebido e como o será, inserindo a nova informação em categorias e classificações pré-existentes. Importa assinalar que, muitas vezes, não se tem consciência da ação dessas convenções, assim como da função de prescrição assumida pelas representações que se impõem sobre o pensamento em construção, dirigindo-o.

Adentrando o universo das representações faz-se destaque à perspectiva de Jodelet (2001), tanto por sua ideia de que, para saber como se comportar no mundo e como dominá-lo intelectualmente, o ser humano cria representações, portanto as considerando como um saber prático que simboliza e interpreta o "objeto" ao qual se refere o sujeito, quanto por salientar as funções das mesmas, como, por exemplo, de possibilitar ao sujeito 'agir sobre o mundo e sobre os outros'.

Ao considerar-se que a representação social diz respeito a um conhecimento que se produz socialmente, que se compartilha com os membros de um grupo, poder-se-ia dizer que, neste caso - no que diz respeito à concepção do psicólogo acerca da psicologia jurídica -, se estaria diante da construção de um conhecimento "natural" ou "ingênuo", o conhecimento do senso comum? Ou dir-se-ia que, por se tratar de especialistas, há ali a construção de um conhecimento "puramente" científico?

Há, parece, uma retroalimentação entre as dimensões do "científico" e do "natural" na constituição do conhecimento. O termo natural está sendo tomado aqui como espontâneo - aquilo que não se põe aprisionado ao ideal de pureza e exatidão do cientificismo - como intencional, como contextualizado e situado. Essa tal retroalimentação poderá ser melhor compreendida, sobretudo, se for tomada como inspiração a proposta de uma psicologia humana enquanto psicologia cultural, conforme indica Bruner (1990). Nela, na psicologia cultural, está posto o significado como conceito central, e o conhecimento do senso comum ou psicologia comum como aquilo a que os pesquisadores da psicologia devem voltar sua atenção. 
Palmonari e Zani (2001) lançam mão da noção de representação para esclarecer as relações existentes entre o social e o cognitivo nas diferentes posições adotadas pelos agrupamentos de psicólogos na I tália no que concerne ao conteúdo científico da Psicologia, bem como à importância dessa ciência na análise dos problemas sociais. Identificam na base dos posicionamentos os processos geradores da representação social, quais sejam: objetivação e ancoragem. Assim também, analisam como tais posições se refletem no trabalho do psicólogo, em seus modos de intervir.

Ao mesmo tempo em que reconhecem a importância das representações sociais para oferecer significados a profissões com surgimento recente, estes autores enfatizam que a influência delas nos diferentes percursos da profissionalização seria menos importante, caso houvesse definições institucionais no momento inicial, ou melhor, no surgimento da profissão.

Já More, Leiva e Tagliari identificam nos estudos no campo da representação social a "procura de uma reflexão teórico-metodológica mais contextualizada às realidades de atuação" (2001, p. 88). Portanto, a Teoria das Representações Sociais traz, para elas, a possibilidade de reflexões teórico-práticas que aproximam 0 conhecimento produzido na pesquisa das realidades da atuação psicológica.

Pensar as práticas profissionais a partir das representações sociais é, segundo Oliveira, Siqueira e Alvarenga, inaugurar um novo olhar sobre ela, "não mais as considerando tão somente como esfera normativa, estritamente técnica e cientificamente determinada. Mas como expressão das subjetividades que se constituem e se expressam inseridas em dado espaço social" (1998, p. 183).

Nas contradições e influências recíprocas entre prática e representação as autoras vislumbram a possibilidade de transformação das práticas profissionais a partir do conhecimento e da mudança das representações. Essa mudança nas representações, por sua vez, só será profunda se as novas práticas persistirem, apesar das defesas que se erguem a favor das representações já existentes. Abric (1994) chega mesmo a afirmar que as representações sociais só se transformam se as novas práticas forem percebidas pelos sujeitos como irreversíveis.

É possível que seja esse o caso dos psicólogos às voltas com a demanda dos sujeitos que lhes chegam e com as exigências de uma instituição judiciária marcada pelo jogo de forças e pelo exercício do controle. Porque, sendo um novo campo de aplicação de seus conhecimentos e estando esses profissionais diante de novas demandas e novas metodologias, como visto com Yamamoto e Campos (1997), necessitam se posicionar, e mais, necessitam sentirse integrantes de um grupo, constituindo sua identidade, ora 
desenvolvendo uma prática inovadora ora repetindo modelos convencionais de intervenção profissional.

\section{Método}

Jovchelovitch (2008) propõe compreender a pesquisa como ato dialógico, que considera tanto o conhecimento do pesquisador quanto o dos sujeitos participantes. Nesse sentido, coloca a imperiosa necessidade que teve a psicologia em libertar-se das amarras do comportamentalismo, indo além do imediatamente observável, buscando entender os processos sociais e psicológicos subjacentes, permitindo que o campo se expresse e que o encontro com o Outro remodele os pressupostos do pesquisador.

Nesse estudo, o Outro está caracterizado pelos "informantes", o grupo de psicólogos que atua no Poder Judiciário de Pernambuco (PJPE) e que está distribuído nos diversos órgãos da instituição. Portanto, propôs-se através dessa pesquisa "desvendar" como os psicólogos do PJPE pensam a Psicologia Jurídica, na instalação do diálogo entre um olhar que se lança a "partir de dentro", de quem pratica a psicologia no judiciário, e um olhar que se lança "a partir de fora", de quem pesquisa a psicologia.

Pelo contato com a Secretaria de Gestão de Pessoas do PJPE e com a rede de conhecimento da pesquisadora foram localizados 74 psicólogos em atuação na instituição. Foram enviados convites para que esses profissionais respondessem a um questionário online. Dos 74 psicólogos contatados, 56 responderam ao instrumento, sendo, portanto, este o número total de sujeitos da pesquisa.

$O$ instrumento online utilizado foi um questionário que continha um item para coletar informações de identificação, permitindo a caracterização da população participante, e itens para empregar a técnica da associação livre.

Esta técnica, segundo Almeida (2005), consiste em apresentar aos participantes um termo indutor, palavra ou expressão que se refere ao objeto representado, a fim de conhecer os elementos que compõem e estruturam a representação. É a organização destes elementos que, para Abric (2004), traz o sentido para o conteúdo da representação.

Assim, no questionário foi solicitado que o participante indicasse seis palavras ou expressões que lhes vinham à mente quando escutavam a expressão indutora "psicologia jurídica", em seguida que organizasse as respostas em ordem de importância e justificasse 0 porquê de tal ordenação.

A população de participantes foi caracterizada em termos de faixa etária, gênero, modalidade de inserção no PJPE e local de trabalho. Assim, constatou-se que $41,07 \%$ dos participantes encontram-se na 
faixa etária que se estende dos 24,5 anos até os 32,5 anos, dos quais $85,71 \%$ são do gênero feminino. No que se refere à inserção e trabalho no PJPE, 83,93\% dos participantes ingressaram na instituição por meio de concurso público para o cargo/função de psicólogo e 48,21\% atuam junto à área da infância e da juventude.

O material coletado na Associação Livre foi tratado a partir do programa de análise de evocação (EVOC). Esse programa localiza as palavras mais frequentes e as relaciona ao grau de importância que Ihes foi atribuído pelos participantes, trazendo informações sobre a organização e a estrutura da representação social, indicando seus elementos centrais e periféricos. Assim, na perspectiva estrutural, as palavras mais frequentes e consideradas mais importantes pelos sujeitos fazem parte da zona central da representação, isto é, são as palavras cujos sentidos são mais compartilhados e estruturam a representação social. As palavras menos frequentes, entretanto, cuja importância é alta, podem indicar uma zona de contraste, isto é, uma tensão entre sentidos de uma representação social. As palavras que têm alta frequência, mas não são consideradas importantes pelos sujeitos fazem parte da zona periférica das representações e, finalmente, aquelas palavras cuja frequência é baixa e não são consideradas importantes na definição do objeto formam a periferia distante da representação social.

\section{Resultados}

A análise dos dados resultantes da associação livre exigiu um primeiro passo visando à organização das respostas emitidas para o termo indutor "psicologia jurídica". Esse passo consistiu na leitura "flutuante" das respostas à fase de hierarquização das palavras ou expressões, que foram ordenadas segundo a importância para melhor definir a psicologia jurídica.

Em seguida o trabalho de agrupamento por similitude, as palavras ou expressões com sentidos semelhantes ou sinônimas foram agrupadas, escolhendo-se um termo para representar o conjunto, a fim de preparar o material que seria analisado com o auxílio do software EVOC. Na análise com o software EVOC, busca-se encontrar a organização dos elementos da representação. O resultado desse tratamento foi registrado no Quadro abaixo composto por quatro quadrantes. Vale lembrar que, a partir da perspectiva estruturalista de Jean-Claude Abric (2004), é essa organização que permite compreender a estrutura da representação social e depreender sentido para seus elementos.

Assim, inferiu-se que, para este grupo, a psicologia jurídica significa um campo de aplicação dos conhecimentos psicológicos e de atuação profissional, que assinala o encontro entre domínios diversos de 
conhecimento e a existência de diferenças e limitações. O que pode ser melhor compreendido com a leitura dos quadrantes.

Observando-se o quadrante 1 (freqüência acima de 6 e ordem média de importância inferior a 3,5 ), aquele no qual se situam os elementos da zona central de uma representação social, é possível supor que os psicólogos do PJPE representam a psicologia jurídica, como aquela psicologia que se faz no âmbito da lei e da Justiça, nos moldes de um trabalho interprofissional, sobretudo dirigido às questões enfrentadas pelas famílias e que, como os demais campos profissionais, suscita o compromisso ético com o sujeito atendido ou até dilemas éticos decorrentes de situações desconhecidas.

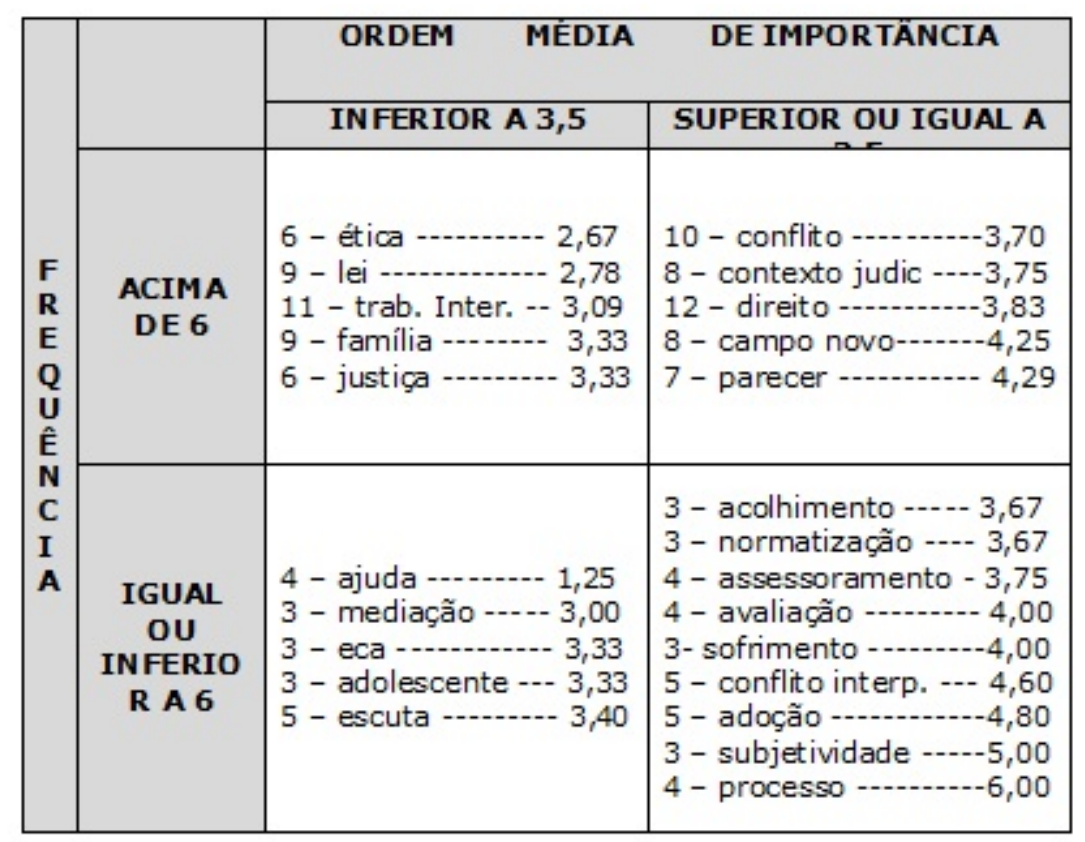

Quadro 1: Frequência e ordem média de importância de palavras para 0 termo indutor "psicologia jurídica" $(\mathrm{N}=55)$.

A respeito do compromisso ético, ao discutirem as implicações da definição da identidade ou identidades do psicólogo nas relações com outros grupos profissionais, Gondim, Luna, Souza, Sobral e Lima informam que "além de um conjunto de conhecimentos e habilidades de domínio próprio, uma profissão precisa ter uma dimensão ética que assegure que esse repertório seja usado somente no interesse coletivo e bem estar comum." (2010, p. 245).

No quadrante de número 2 (freqüência acima de 6 e ordem de importância superior ou igual a 3,5) encontram-se os elementos periféricos mais importantes, é a primeira periferia. Nesse caso, os elementos do segundo quadrante ampliam, mas ao mesmo tempo reforçam os elementos centrais, sobretudo ao se referirem ao contexto judiciário e ao direito ou aos direitos. 
Uma vez mais as ideias trazidas se dirigem à caracterização de uma prática, realçando que ela se faz em um campo novo, no qual se lida com conflitos e que se concretiza na elaboração de um parecer. Importa notar que este último termo, além de frequente nas associações livres, é uma constante no texto das leis estaduais que, nas décadas de 1990 e 2000, regulamentaram a presença do psicólogo no judiciário pernambucano. Portanto, o termo parecer aponta algo característico a esse campo, algo que auxilia a tornar concreto um objeto pouco definido: a psicologia jurídica. Supõe-se estar em cena o processo de constituição de uma representação social, designado de objetivação. Ao concretizar no ato de emitir um parecer os sentidos de psicologia jurídica os sujeitos de certo modo buscam na regulamentação institucional os elementos de ancoragem do novo.

Inferiu-se também que esse campo ainda está se constituindo e é delimitado por dizer respeito a questões judiciais e legais. Essas questões ora parecem ser encaradas como especificidades do campo, aquilo que o diferencia de outros campos de aplicação, e que dizem respeito ao novo, à nova inserção profissional; ora como dificuldades, ou como gerador de conflitos, o que foi referido pelos participantes, por exemplo, no cumprimento de prazos ou no limite de tempo.

A "zona dos elementos contrastados", situada por Abric (2003) no terceiro quadrante (freqüência igual ou inferior a 6 e ordem de importância inferior a 3,5), pode, segundo esse autor, indicar a existência de um subgrupo portador de uma representação diferente. No caso em análise ganha destaque, nesse quadrante, a associação da psicologia jurídica aos termos ajuda e escuta.

A Psicologia Jurídica, ou melhor, o sentido que a ela parece se associar nesses conjuntos de termos ou expressões sinalizaria que, ao adentrar outro campo de saber e prática, aquele delineado pelo Direito, a psicologia depararia com o desafio da convivência com o diferente e com o fato de que essa convivência pode trazer conflitos, mas também o dialogo e a inovação. Isso, talvez, exija uma postura "inter", uma multiplicidade de perspectivas e que foi evidenciado no primeiro quadrante. Assim, a inserção nesse "campo outro" pode trazer a possibilidade de contribuição da psicologia tanto ao saber e às práticas jurídicas, quanto à população que aí é atendida.

É importante também sublinhar a presença de termos que se referem à adolescência, podendo ser pensado que aqui se concentram ideias que caracterizam uma psicologia voltada ao sujeito atendido e à tensão entre voltar-se a ele ou aos objetivos da instituição, à semelhança do que foi vivido pelo psicólogo em outras áreas, como a organizacional por exemplo. O compromisso com o sujeito atendido é exposto por Brito da seguinte forma: 
É necessário pensar, também, na necessidade de afastamento dos psicólogos de uma interferência legitimadora de controles sociais, exclusões ou segregações, no rumo de uma aproximação com o desenvolvimento dos sujeitos, como indica nosso Código de Ética Profissional. Colaborar com os que chegam ao Sistema de Justiça para que possam compreender seu lugar subjetivo, seu vínculo com a sociedade, assim como seus direitos e deveres pertinentes, sugere uma função comprometida com esses sujeitos de direito (2005, p. 15).

Os termos: adolescente, Estatuto da Criança e do Adolescente e mediação evidenciam também temas concernentes ao judiciário, assim como se viu no quadrante anterior. Inclusive trazem à lembrança de que foi para atuar junto à infância e juventude que o cargo de psicólogo foi criado no PJPE. Entretanto, faz-se a ressalva de que a mediação nem é originária, nem adstrita a esse contexto judiciário.

Assim, a concepção expressa pelo grupo, nesta fase da pesquisa, pareceu compreender uma intervenção que se faz numa instituição e se volta tanto para ela, quanto para os sujeitos atendidos. A esse respeito Fávero, Melão e J orge dirão que:

Trabalhando em uma instituição em que o sofrimento se põe cotidianamente nas situações atendidas, suas funções, tais como as do Serviço Social, alargam-se para além da prática pericial, apresentando-se enquanto um espaço de escuta do outro, uma escuta que deve ser crítica (2005, p. 110).

A intervenção assim delineada implicaria, para a população pesquisada, além de uma proposta teórico-metodológica diversificada, o compromisso ético com os sujeitos atendidos, tendo como princípios a garantia e defesa dos Direitos Humanos.

O voltar-se ao outro para acolhê-lo, para ajudá-lo e orientá-lo; o compromisso ético com o sujeito atendido que nessas expressões se evidenciam encontram-se previstos como atribuição do especialista da psicologia jurídica na resolução CFP no 13/2007, quando indica que a orientação do dado psicológico não só se faz à instituição, mas também ao sujeito atendido. Costa constatou que, em Santa Catarina, mais da metade dos profissionais que atuam em organizações de justiça e que participaram da pesquisa "não orienta sua clientela acerca da utilização dos resultados obtidos a partir de sua atuação" (2006, p. 95).

No quadrante de número 4 (freqüência igual ou inferior a 6 e ordem média de importância superior ou igual a 3,5), no qual se situa a terceira periferia, encontram-se palavras que se referem ao universo do Direito: normatização, adoção, processo, e da Psicologia: 
acolhimento, assessoramento, avaliação, subjetividade, além daquelas que se referem ao sujeito que recorre a esse serviço: sofrimento, conflito interpessoal: palavras que reforçam os sentidos expressados nos conjuntos anteriores.

Assim as expressões parecem revelar a compreensão da Psicologia Jurídica como um campo de prática que requer tanto novas quanto tradicionais estratégias metodológicas, as quais se fazem emoldurar pelo universo jurídico, pelas características institucionais.

Situar a psicologia jurídica no contexto judiciário, ou naquilo que diz respeito à lei e à Justiça, pode ser entendido como tentativa de dar forma ou de constituir, como assinalado por Santos (2005), um núcleo figurativo ou "imageante" para ela. Assim também, ao caracterizá-la como uma prática ou uma intervenção psicológica que se faz em equipe, que redunda em pareceres e que se mostra modelada em diferentes procedimentos, como a mediação ou o assessoramento, pode indicar a tentativa de objetivar esse "campo novo".

Não é sem precedentes tal imagem para a psicologia jurídica. Vê-se que está embasada na própria definição para os termos jurídico e judiciário, encontrada nos dicionários de língua portuguesa, no que tange à sua identificação com o universo da lei, da Justiça e dos direitos. Quanto ao fato de estar associada a uma prática de parecer e trabalho em equipe, pode-se lançar mão da própria legislação que normatiza a entrada do profissional da psicologia na instituição judiciária pernambucana e as atribuições que aí deverá assumir e como pode ser constatado no texto da lei federal no 8.069/90, Estatuto da Criança e do Adolescente.

Então, dir-se-ia que a representação se enraíza nos conhecimentos e valores existentes na cultura, e o novo ganha um sentido. Estar-seia, pois, diante da atribuição de sentido que se faz no processo da ancoragem, ao se constituir uma representação social (SANTOS, 2005). Também assim a literatura que trata da psicologia jurídica buscará caracterizá-la a partir de referência à história de suas práticas. Bernardi dirá:

A análise da história da implantação da Psicologia no Tribunal de Justiça de São Paulo pode nos auxiliar nesta tarefa de compreensão da relação Psicologia-Direito. Trata-se do relato de uma experiência localizada, recente e contemporânea, mas que ilustra que assim como a Medicina adentrou o fórum via conceito de loucura, a Psicologia adentrou via os problemas da família no trato com seus filhos (1999, p. 104-105).

A história da psicologia é marcada por solicitações políticas e sociais que visavam, e talvez ainda visem produzir uma sociedade ordeira e 
produtiva. Nessa perspectiva, família, crianças e adolescentes foram tomados como objetos de interesse e intervenção desta ciência. É também nessa história que o parecer como elemento de sentido para a psicologia pode ser situado, como assinalado por Rovinski (2009), ao remeter a prática da psicologia jurídica para o seu início na área criminal com a vinda dos psicólogos estrangeiros, quando simultaneamente também estavam em curso as produções de conhecimento nos primeiros laboratórios de psicologia do país.

O potencial de transformação trazido pelo encontro e a inter-relação entre domínios de saber e campos de práticas diversos foi destacado por Bernardi que, ao discutir a avaliação psicológica no âmbito das instituições judiciárias, demonstrou a necessidade de tomada de consciência por parte dos psicólogos acerca das implicações de sua intervenção:

[...] a interface dos conhecimentos de psicologia, direito e serviço social podem auxiliar na manutenção ou na mudança de valores e crenças que perpassam a atuação judiciária. As implicações ideológicas do trabalho são inevitáveis, e por isso mesmo essenciais para a análise crítica das atividades desenvolvidas nesse escopo de saber e poder judiciário. Representações sociais sobre família, infância e outros conceitos podem ser fortalecidos ou modificados pelo conhecimento transmitido nos laudos psicológicos, cujo conteúdo revela as concepções de sociedade, ciência e de homem que dão suporte a ação profissional. Disso resulta a necessária precaução sobre os efeitos políticos e ideológicos da atuação dos psicólogos, que vão além das decisões caso a caso $(2005$, p. 75$)$.

Retoma-se aqui a reflexão feita a partir das ideias de Rovinski (2009), sobre a multiplicidade de objetos da psicologia jurídica e a fragmentação de seu campo de investigação, pois ao lado das expressões e palavras que evocam a coexistência de diferentes abordagens teórico-metodológicas, há a expressão de diferentes temáticas de trabalho, de diferentes sujeitos e questões que 0 perpassam aos quais deve se dirigir a intervenção do psicólogo.

Em estudo realizado em âmbito nacional, embora não estivessem se reportando à área jurídica especificamente, Gondim, Bastos e Peixoto observam que as demandas sociais hoje exigem uma abordagem multidisciplinar do sujeito situado histórica e culturalmente, o que vai além da compreensão de sua dinâmica intrapsíquica. Eles constatam que:

Se o exercício profissional e a ampliação das áreas de atuação demandam amadurecimento teórico ainda não disponível na psicologia, a alternativa é buscar a integração dos modelos 
teóricos existentes e criar novos arranjos de intervenção para dar suporte à atuação do psicólogo (2010, p. 193).

Diante desta multiplicidade e diversidade, caberia a discussão sobre uma atuação psicológica marcadamente caracterizada pela avaliação e o exame, embora não se possa desconsiderar que são indicadas pelos participantes outras modalidades de atuação e de estratégias de intervenção, como o trabalho em equipes multidisciplinares e a mediação por exemplo.

Esta marca tanto pode ser tomada como uma especificidade da prática psicológica nesse campo, como pode consistir na convivência entre modelos tradicionais, que remontem aos primórdios da psicologia no Brasil e a inovação nos formatos da atuação, a tentativa de construção de novos modelos, trazidas pela inserção em diferentes setores, em diferentes instituições. Esta coexistência do tradicional com a tentativa de construção do novo também faze pensar: estaria em desenvolvimento uma prática submetida conforme alertara França (2004), decorrente de uma relação de subordinação entre Direito e Psicologia? Ou haveria uma transição entre o convencional e o novo, conforme aludido por Yamamoto e Campos (1997)?

Para enfrentar essa encruzilhada fez-se recurso à Teoria da Representação Social, pensando, sobretudo, na possibilidade de interpenetração de conhecimentos: sejam conhecimentos de diferentes ciências, passados e presentes, sejam conhecimentos de senso comum, eles se irrigam nas comunicações cotidianas e formam um substrato para a compreensão do "aparente" novo. Vejam-se as palavras de Moscovici:

\begin{abstract}
Todos os sistemas de classificação, todas as imagens e todas as descrições que circulam dentro de uma sociedade, mesmo as descrições científicas, implicam um elo de prévios sistemas e imagens, uma estratificação na memória coletiva e uma reprodução na linguagem que, invariavelmente, reflete um conhecimento anterior e que quebra as amarras da informação presente (2003, p. 37).
\end{abstract}

\title{
4 Algumas considerações
}

Em síntese, para esse grupo de profissionais a psicologia jurídica significa um campo de aplicação dos conhecimentos psicológicos e de atuação profissional que está se constituindo e que está delimitado por dizer respeito às questões legais, sendo um campo marcadamente de interface. Para compreendê-lo e defini-lo, os psicólogos lançam mão daquilo que caracterizou a Psicologia como ciência e profissão ao longo de sua história, tanto expressando ideias 
tradicionais como avaliação e parecer, quanto, ideias novas como o trabalho interprofissional e a mediação. A tensão entre diferentes domínios de saber e entre o novo e o tradicional foi evidenciada pela preocupação com a dimensão ética e pela presença do termo conflito. Assim foi-se levado a compreender que apesar de se tratar de "especialistas", a aplicação de uma ciência a novos contextos e demandas abre espaço para que construam socialmente, ao lado das reformulações teóricas e técnicas, um conhecimento compartilhado que funciona como guia para ação e que lhes proporciona uma identidade de grupo no convívio com profissionais de outras áreas. Portanto, é a convivência entre conhecimento científico e conhecimento comum que parece se evidenciar. E, considerando, as constantes mutações sociais e econômicas que repercutem no mundo do trabalho, é-se levado a acreditar que as profissões se transformam e que as representações sociais irão exercer, em diferentes momentos e não só no surgimento de novas profissões, seu papel de oferecer-Ihes significados.

No que concerne ao conflito entre voltar-se ao outro para acolhê-lo, para ajudá-lo e orientá-lo ou atender aos ditames da instituição, fica a reflexão sobre o compromisso ético com o sujeito atendido, evidenciado nas expressões apresentadas e previsto como atribuição do especialista da psicologia jurídica na resolução CFP no 13/2007, e a realização da orientação do dado psicológico ou da entrevista devolutiva.

Assim, conclui-se que ao reconhecer os impasses e as dificuldades, o profissional tem oportunidade de reformular seu saber e recriar sua prática, que, ao se manter constante, possibilita que as representações sociais sejam modificadas e que outras práticas sejam inauguradas.

\section{Referências}

ABRIC, J. C. L'organisation interne des représentations sociales: système central et système périphérique. In: Guimelli, C. Structures et transformations des Représentations Sociales, Lausanne, Delachaux et Niestlé, 1994, p. 73-84

. J. C. La recherche du noyau central et de la zone muette des représentations sociales. In: J-C. Abric (org.). Méthodes d'études des représentations sociales. Érès: Ramonville Saint-Agne, 2004. Traduzido por Maria de Fátima de Souza Santos para uso de pesquisa.

ALMEIDA, A. M. A pesquisa em representações sociais: fundamentos teórico-metodológicos. In: SANTOS, M. F. de S.; ALMEIDA, L. M. (Org.) Diálogos com a teoria da representação social. Recife: Editora Universitária da UFPE, 2005, p. 117-160. 
ARANTES, E. M. Pensando a Psicologia aplicada à Justiça. In: BRANDÃO, E. P.; GONÇALVES, H. S. (Org.) Psicologia J urídica no Brasil. Rio de Janeiro: NAU, 2004. p. 15-49.

. ARANTES, E. M. Mediante quais práticas a Psicologia e o Direito pretendem discutir a relação? Anotações sobre o malestar.

em:

<http://www.crprj.org.br/documentos/2007artigo-esther-

arantes.pdf>. Acesso: em agosto 2009.

ASSIS, M. M. Psicologia judiciária: da prática forense à instituição acadêmica. In: BRITO, L. M. T. (org). Temas de psicologia jurídica. Rio de Janeiro: Relume Dumará, 1999. p. 73 - 85.

BERNARDI, D. C. F. Histórico da inserção do profissional psicólogo no Tribunal de Justiça do estado de São Paulo - um capítulo da psicologia jurídica no Brasil. In: BRITO, L. M. T. (org). Temas de psicologia jurídica. Rio de Janeiro: Relume Dumará, 1999. p. 103 13.

- A construção de um saber psicológico na esfera do Judiciário Paulista: um lugar falante. In: FÁVERO, E. T.; MELÃO, M. J. R. e JORGE, M. R. T. (Org). O serviço social e a psicologia no judiciário: construindo saberes, conquistando direitos. São Paulo: Cortez, 2005.

Avaliação psicológica no âmbito das instituições judiciárias. In: CRUZ, R. M.; MACIEL, S. K. e RAMIREZ, D. C. O trabalho do psicólogo no campo jurídico. São Paulo: Casa do Psicólogo, 2005, p. 71-80.

BRASIL. Resolução no 13/ 2007. Conselho Federal de Psicologia, 20 de dezembro de $2000 . \quad$ Disponível em <http://www. pol.org.br/pol/export/sites/default/pol/legislacao/legisla caoDocumentos/resolucao2007_13.pdf>. Acesso: em 01 nov. 2010. BRITO L. M. T. Apresentação. In:___. (org) Temas de psicologia jurídica. Rio de Janeiro: Relume Dumará, 1999. p. 1118.

. L. M. T. Reflexões em torno da Psicologia Jurídica. In: CRUZ, R. M.; MACIEL, S. K. e RAMIREZ, D. C. O trabalho do psicólogo no campo jurídico. São Paulo: Casa do Psicólogo, 2005, p. 9-17.

BRUNER, J. Actos de significado: para uma psicologia cultural. Lisboa: Edições 70, 1990.

CANGUILHEM, G. O que é a psicologia? Impulso: Revista de Ciências Sociais e Humanas, v. 11 , n. 26, pp. 11-26, Piracicaba, $1999 . \quad$ Disponível em: <http://www.unimep.br/phpg/editora/revistaspdf/impulso26.pdf> Acesso em: 19 ago. 2009.

COSTA, F. N. O trabalho dos psicólogos em organizações de justiça do Estado de Santa Catarina. 154f, 2006. Dissertação (Mestrado em Psicologia) Universidade Federal de Santa Catarina, Florianopolis. 
FÁVERO, E. T.; MELÃO, M. J. R. e JORGE, M. R. T. (Org). O serviço social e a psicologia no judiciário: construindo saberes, conquistando direitos. São Paulo: Cortez, 2005.

FOUCAULT, M. A verdade e as formas jurídicas. Rio de Janeiro: NAU Editora, 2003.

FRANCA, F. Reflexões sobre psicologia jurídica e seu panorama no Brasil. Psicologia Teoria e Prática. [online]. jun. 2004, vol.6, no.1, pp.73-80. Disponível em: <http://pepsic.bvspsi.org. br/scielo.php?script=sci arttext\&pid $=S 151636872004000100$ 006\&lng =pt\&nrm=iso >. ISSN 1516-3687. Acesso em: 08 Maio 2009. GONDIM, S. M. G.; BASTOS, A. V. B.; PEIXOTO, L. S. A. Áreas de atuação, atividades e abordagens teóricas do psicólogo brasileiro. In: BASTOS, A. V. B.; GONDIM, S. M. G. O trabalho do psicólogo no Brasil. Porto Alegre: Artmed, 2010, p. 174-199.

GONDIM, S. M. G.; LUNA, A. F.; SOUZA, G. C.; SOBRAL, L. C. S.; LIMA, M. S.. A identidade do psicólogo brasileiro. In: BASTOS, A. V. B.; GONDIM, S. M. G. O trabalho do psicólogo no Brasil. Porto Alegre: Artmed, 2010, p. 223-247.

HELOANI, R.; MACÊDO, K. B.; CASSIOLATO, R. O exercício da profissão: características gerais da inserção profissional do psicólogo. In: BASTOS, A. V. B.; GONDIM, S. M. G. O trabalho do psicólogo no Brasil. Porto Alegre: Artmed, 2010, p. 107-130.

J ACÓ-VILELA, A. M. Os primórdios da psicologia jurídica. In: BRITO L. M. T. (Org). Temas de psicologia jurídica. Rio de Janeiro: Relume Dumará, 1999, p. 11 - 18.

JODELET, D. Representações sociais: um domínio em expansão. In: 2001. pp. 17-44.

As representações sociais. Rio de Janeiro: EdUERJ,

JOVCHELOVITCH, S. O estudo dos saberes na vida cotidiana. In Os contextos do saber: representações, comunidade e cultura. Petrópolis: Vozes, 2008. p. 259-299.

MIRANDA JÚNIOR, H. C. Psicologia e Justiça: A psicologia e as práticas judiciárias na construção do ideal de justiça. Psicologia Ciência e Profissão. Brasília: Conselho Federal e Regionais de Psicologia, Ano 18, n. 1, 1998, p. 28-37.

MORE, C. O. O.; LEIVA, A. C.; TAGLIARI, L. V.. A representação social do psicólogo e de sua prática no espaço público-comunitário. Paidéia (Ribeirão Preto), Ribeirão Preto, v. 11, n. 21, 2001. Disponível em <http://www.scielo.br/scielo.php?script=sci_arttext\&pid=S0103$863 \times 2001000200010 \& \mathrm{lng}=\mathrm{pt} \& \mathrm{nrm}=\mathrm{iso}>$. Acesso em: $13 \mathrm{mar}$. 2011.

MOSCOVICl, S. O Fenômeno das Representações Sociais. In: Representações Sociais: investigações em psicologia social. Petrópolis: Vozes, 2003. p. 29-109. 
PALMONARI, A.; ZANI, B. As representações sociais no campo dos psicólogos. In: JODELET, D. (Org.). Representações sociais. Rio de Janeiro: EdUERJ, 2001, p. 261-279.

ROVINSKI, S. L. R. Introdução. Psicologia Jurídica no Brasil e na América Latina: dados históricos e suas repercussões quanto à avaliação psicológica. In: ROVINSKI, S. L. R.; CRUZ, R. M. Psicologia jurídica: perspectivas teóricas e processos de intervenção. São Paulo: Vetor, 2009, p. 11-22.

SANTOS, M. F. S. A teoria das representações sociais. In: SANTOS, M. F. S; Almeida, L. M. Diálogos com a teoria das representações sociais. Recife: EDUFPE/EDUFAL, 2005, p. 13-38.

YAMAMOTO, O. H.; CAMPOS, H. R. Novos espaços, práticas emergentes: um novo horizonte para a psicologia brasileira? Psicologia em Estudo, Maringá, v. 2, n. 2, 1997, p. 89-111.

\section{Endereço para correspondência}

\section{Verônica Cecilia Alves da Silva Mafra}

Tribunal de Justiça de Pernambuco, Vara Regional da Infância e da Juventude da $1^{\underline{a}}$ Circunscrição J udiciária.

Rua J oão Fernandes Vieira, 405 - Boa Vista, Recife - PE. CEP: 50050-200.

Endereço eletrônico: nona.cecilia@ig.com.br

\section{Maria de Fátima de Souza Santos}

Universidade Federal de Pernambuco, Centro de Filosofia e Ciências Humanas,

Departamento de Psicologia.

Av. Prof. Moraes Rego, 1235 - Cidade Universitária, Recife - PE. CEP: 50670-901.

Endereço eletrônico: mfsantos@ufpe.br

Recebido em: 28/03/2011

Reformulado em: 14/07/2012

Aceito para publicação em: 25/07/2012

Acompanhamento do processo editorial: Deise Mancebo

\section{Notas}

* Mestre em Psicologia, Professora do Departamento de Psicologia da Faculdade de Ciências Humanas ESUDA, psicóloga do Poder Judiciário de Pernambuco.

** Doutora em Psicologia, Professora do Departamento de Psicologia e do Programa de Pós-graduação em Psicologia da Universidade Federal de Pernambuco.

Esta versão do texto O que é a psicologia? de Canguilhem foi publicada no no 26 da Revista Impulso da Universidade Metodista de Piracicaba. Originalmente foi publicada versão em português em 1972 no no 30/31, jul/dez, da Revista Tempo Brasileiro. 